\title{
MEWDS - «enfermedad similar a la gripe» de la retina
}

\section{MEWDS - a retinal "flu-like illness"}

\author{
Sanjay Kumar-Mishra y Ashok Kumar* \\ Departamento de Oftalmología, Army College of Medical Sciences \& Base Hospital, Delhi, India
}

Varón de 25 años, que acudió a la consulta externa de oftalmología por visión borrosa en el ojo izquierdo de 3 días de evolución. El paciente tiene antecedente de rinitis de etiologia viral 15 días previos a su consulta, que remitió espontáneamente sin ningún medicamento. En la evaluación, tenía una agudeza visual mejor corregida (AVMC) de 6/6 en el ojo derecho y 6/12 en el ojo izquierdo, con segmento anterior normal en ambos ojos. La evaluación del fondo de ojo del ojo izquierdo reveló múltiples puntos blancos, redondos y discretos, en el epitelio pigmentario de la retina alrededor del área macular (Fig. 1 A). En la autofluorescencia del fondo de ojo, las lesiones eran hiperautofluorescentes, y la angiografía con fluoresceína mostró un patrón de hiperfluorescencia múltiple, puntiforme y en forma de corona, correspondiente a la lesión blanca característica del síndrome de múltiples puntos blancos evanescentes (MEWDS, Multiple Evanescent White Dot Syndrome) (Fig. 1 B). El paciente fue evaluado para descartar otras posibles causas de lesiones blancas en el polo posterior, como infección o inflamación de la retina o de la coroides, pero todas las investigaciones fueron normales, lo que confirmó el diagnóstico de MEWDS. El paciente fue tratado de manera conservadora, ya que en estos casos se produce una mejoría espontánea. A las 2 semanas de la presentación, se observó una resolución sustancial de las lesiones blancas (Fig. $1 \mathrm{C}$ ), y hubo resolución completa a las 4 semanas después de la presentación, con una recuperación de la $A V M C$ a 6/6 en el ojo izquierdo sin ningún tratamiento (Fig. 1 D).

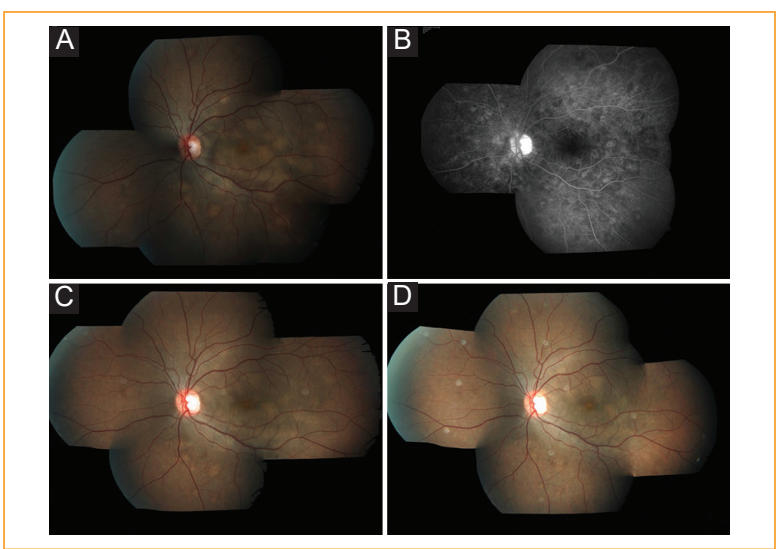

Figura 1. A: fotografía de fondo de ojo del ojo izquierdo que muestra múltiples puntos blancos, redondos y discretos, en el epitelio pigmentario de la retina alrededor del área macular. B: angiografía con fluoresceína del ojo izquierdo que muestra un patrón de hiperfluorescencia múltiple, puntiforme y en forma de corona, correspondiente a la lesión blanca característica del síndrome de múltiples puntos blancos evanescentes (MEWDS). C: fotografía de fondo de ojo del ojo izquierdo 2 semanas después de la presentación, que muestra una resolución sustancial de las lesiones blancas. D: fotografía de fondo de ojo del ojo izquierdo 4 semanas después de la presentación, que muestra la resolución espontánea completa de las lesiones de puntos blancos sin ningún tratamiento.

EI MEWDS es una retinopatía aguda, en general unilateral y autolimitada que afecta predominantemente a las regiones macular y periférica media de las mujeres jóvenes, provocando una pérdida visual de leve a moderada ${ }^{1}$. Los rasgos característicos de la MEWDS 
incluyen múltiples puntos blancos y discretos en el epitelio pigmentario de la retina o de la retina externa en el polo posterior, precedidas por un pródromo de enfermedad viral, con autofluorescencia del fondo de ojo que revela hiperautofluorescencia y patrón de puntos hiperfluorescentes en forma de corona en la angiografía con fluoresceína ${ }^{2}$. La mayoría de los pacientes con MEWDS tienen una resolución espontánea de todas las lesiones, con una mejoría de la agudeza visual en semanas, y rara vez requieren tratamiento, al igual que se observa en la enfermedad similar a la gripe ${ }^{3}$. El uso inmediato de modalidades diagnósticas apropiadas con la exclusión temprana de imitadores del MEWDS puede prevenir un posible tratamiento innecesario en la «enfermedad similar a la gripe de la retina».

\section{Conflicto de intereses}

Los autores declaran que no existen conflictos de intereses.

\section{Responsabilidades éticas}

Protección de personas y animales. Los autores declaran que para esta investigación no se han realizado experimentos en seres humanos ni en animales.

Confidencialidad de los datos. Los autores declaran que han seguido los protocolos de su centro de trabajo sobre la publicación de datos de pacientes.

Derecho a la privacidad y consentimiento informado. Los autores han obtenido el consentimiento informado de los pacientes y/o sujetos referidos en el artículo. Este documento obra en poder del autor de correspondencia.

\section{Bibliografía}

1. Hua R, Chen K, Liu LM, Liu NN, Chen L, Teng WP. Multi-modality imaging on multiple evanescent white dot syndrome - a spectralis study. Int J Ophthalmol. 2012;5:644-7.

2. Jampol LM, Sieving PA, Pugh D. Multiple evanescent white dot syndrome. I. Clinical findings. Arch Ophthalmol. 1984;102;5:671-4

3. Tavallali A, Yannuzzi LA. MEWDS, common cold of the retina. J Ophthalmic Vis Res. 2017;12:132-4. 